\title{
Research on the Four-Dimensional Decomposition of China's Manufacturing Export Growth
}

\author{
Dong Tianhao ${ }^{1, *}$, Deng Jing ${ }^{2}$ \\ ${ }^{1}$ Department of Economics, Nanjing University of Aeronautics and Astronautics, Nanjing, China \\ ${ }^{2}$ Department of Economics, Nanjing University of Aeronautics and Astronautics, Nanjing, China \\ *Corresponding author. Email: wxdongtianhao@163.com
}

\begin{abstract}
Based on the dynamic decomposition framework of export duration from the perspective of micro-firm export behaviour, this thesis divides the export trade of an economy into four dimensions: Entry, Exit, Survival and Deepening. After redefining the decomposition rules, this thesis analyses the export growth of China's manufacturing industry based on the export data of China's manufacturing industry in the past twenty-four years. After decomposition, the following conclusions can be obtained: (1) under the four-dimensional dynamic decomposition, China's manufacturing export trade and export growth are both dominated by the intensive margin; (2) the changes in the number of trade relations and the intensification rate indicate that China's manufacturing exports are more affected by external shocks; (3) the rate of deepening reflects that Chinese manufacturing export companies may not have advantages in long-term international competition.
\end{abstract}

Keywords: Export growth, Manufacturing, Marginal decomposition, Export behaviour

\section{INTRODUCTION}

In the context of the new economic normal, how to maintain a stable and continuous growth trend in China's export trade for a long period of time in the future is a hot topic. Based on actual product export data, the manufacturing level of China has far surpassed the current international average level of national income, but is still in the stage of scale development. Although the industrial system has a complete range of categories, the modernization levels of different departments show a significant gap. In certain industry sectors, low-end manufacturers with a huge domestic industrial chain and unique advantages in solving employment problems are quite different from advanced manufacturers who have more opportunities to engage in international competition and absorb international experience. Currently in the world, although some economies currently have the potential to develop manufacturing and further expand manufacturing exports, they cannot match China in terms of local size, technology or supply chain. However, it should also be recognized that in order to promote the future development of China's manufacturing industry, it is necessary to have a more thorough understanding and a deeper grasp of the current situation of China's manufacturing export trade.
The research on the marginal decomposition of exports originated from the introduction of heterogeneous enterprise trade theory in the early $21 \mathrm{st}$ century. At present, there are roughly three kinds of ideas for the marginal decomposition framework for export growth research. The first idea is the multi-period comparative definition method represented by AmurgoPacheco and Pierola (2008) [1]. Huang Xianhai and Zhou Junzi (2011) use this method to further extend the expansion margin to the two dimensions of geography and product. The results show that prices have a positive role in promoting geographic expansion, which occupies a dominant position in the growth of Chinese product exports, and this role will be reversed by economic fluctuations. At the same time, economic fluctuations also strengthen the inhibitory effect of trade in intermediate products [2]. Research results show that price has a positive effect on geographic expansion which is dominant in the growth of Chinese exports, and this effect will be reversed by economic fluctuations. At the same time, economic fluctuations have also strengthened the inhibitory effect of trade in intermediate products. The second idea is the ternary marginal method developed by Shi Bingzhan (2010) on the basis of the binary marginal method of Hummels and Klenow (2005) [3], which decomposes the single-year trade share growth 
of the research target country into breadth, price and quantity relative to the world average. The research results show that the intensive margin is dominant in China's export growth, while the price impact is relatively small [4]. The third idea is represented by Amiti and Freund (2007) and Bernard et al. (2009), which considers time dynamics on the basis of a binary margin. The former research found that the growth of Chinese exports to the United States is dominated by the intensive margin [5]. The latter research showed that the expansion margin dominates the overall US foreign trade changes, but the intensive margin dominates trade changes in the shorter term [6]. The mainstream framework in the current field of marginal decomposition research is the second idea, and the framework selected in this study is the third idea, which is mainly to examine the characteristics of changes in the dual marginal structure of export growth in the short term.

Based on the original binary marginal decomposition method, this thesis uses the dynamic decomposition method combined with the export duration to derive the formula derivation and rule definition of the fourdimensional decomposition framework of Entry, Exit, Survival and Deepening. Based on the export data of China's manufacturing industry from 1996 to 2019 in the UN Comtrade database, this thesis analyses the fourdimensional dynamic analysis of China's manufacturing export growth from the perspectives of export value and trade volume.

\section{FOUR-DIMENSIONAL DYNAMIC DECOMPOSITION FRAMEWORK}

This study refers to the research framework of Besedes and Prusa (2011) [7] and Zhang Feng et al. (2019) [8] to carry out a four-dimensional decomposition of export growth. The export relationship of a single economy in period $t$ can be divided into three parts: (1) export relationships continuously surviving from period $t-1$ to period $t$, (2) export relationships that survives in period $t-1$ but exits in period $t$, and (3) newly entered export relationships in period $t$. If We use $s_{t}, d_{t}$ and $\varepsilon_{t}$ to denote the quantities of the above three types of export relations in period $t$, and $n_{t}$ to denote the total quantity of different export relations, then $n_{t}=s_{t}-d_{t}+\varepsilon_{t}$, and the export growth of a single economy from period $t$ to period $t+l$ can be expressed as

$$
\begin{aligned}
& V_{t+1}-V_{t} \\
= & s_{t+1}\left(v_{s, t+1}-v_{s, t}\right)-d_{t+1} v_{d, t+1}+\varepsilon_{t+1} v_{\varepsilon, t+1}
\end{aligned}
$$

wherein $V_{t}$ represents the total export value of the economy in period $\mathrm{t}$, and $v_{s, t}, v_{d, t}$ and $v_{\varepsilon, t}$ represents export value of above three types of export relations. The biggest difference between different types of export relations each year is reflected in different durations, which are correspondingly manifested in the risk functions. Since the risk functions of these export relations can be estimated at the industry level, Equation (1) can be rewritten as follows:

$$
\begin{aligned}
& V_{z, t+1}-V_{z, t} \\
= & \sum_{i=1}^{I} \underbrace{\left[\left(1-h_{z, t+1}^{i}\right) n_{z, t}^{i}\right]}_{\text {survival-stayers }} \underbrace{\left(v_{z s, t+1}^{i}-v_{z s, t}^{i}\right)}_{\text {deepening }} \\
- & \sum_{i=1}^{I} \underbrace{\left[\left(h_{z, t+1}^{i} n_{z, t}^{i}\right) v_{z d, t}^{i}\right]}_{\text {failure }}+\underbrace{\varepsilon_{t+1} v_{z \varepsilon, t+1}^{0}}_{\text {entry }}
\end{aligned}
$$

wherein $z$ represents the sub-industry of specified export relationship, I represents the maximum value of durations of the potential export relationships in period $t$, and the superscript $i$ represents the duration of specified export relationship. $h_{z, t}$ represents the risk rate of export relationships of different durations in industry $z$ that exits in period $t$. If the risk function of the export relationship is expressed in the form of non-parametric estimation, we can get $h_{z, t}^{i}=d_{z, t}^{i} / n_{z, t}$. More specifically, since the duration in the first year of export is 0 and it is unlikely to fail, it can be defined as $h_{z, t}^{0}=0$

The rewritten Equation (2) takes the duration into consideration in the structural decomposition of export growth, so as to incorporate the dynamic changes in exports caused by time differences into the study. Strictly speaking, after decomposing according to the Equation (2), annual export growth of a single economy can be divided into three parts, wherein Survival and Deepening belongs to the intensive margin, and the latter Entry and Exit constitute the expansion margin. Survival and Deepening can be further divided into the two dimensions, namely, the number of Survival export relations and the Deepening of the average export value, which together with Enter and Exit constitute a fourdimensional dynamic decomposition.

\section{FOUR-DIMENSIONAL DECOMPOSITION ANALYSIS OF CHINA'S MANUFACTURING EXPORTS}

After screening and merging the target market economies, based on China's export data to 192 economies in the world in the UN Comtrade database, a four-dimensional dynamic decomposition of China's manufacturing export growth is carried out. More specifically, if an export product was classified as Exit or Survival and Deepening in 1997, it will default to Entry in 1996.

\subsection{Definition of Decomposition Rules}

Before decomposing specific export data, we should first define the dimensional division rules of export products in the destination market. Related literature in the past mostly adopted the two-year rule of Bernard and Jensen (2007) when classifying the dynamic export behaviour of enterprises [9]. However, this classification method will result in that export products that only survive for one period actually belong to multiple 
classifications. Although the three-year rule adopted by Gao Lingyun et al. (2017) [10] and Zhang Feng et al. (2019) [8] nominally considers the export of a single year and makes each subset a mutually exclusive complete closed set, it actually ignores some short-lived break situation, so that there is no one-to-one correspondence between Entry and Exit, thus underestimating the entry, exit and other dimensions. Therefore, this study combines the above two rules to redefine the export status of products in the same target market in period $t$ : (1) products that are not exported in period $t-1$ but exported in period $t$ are defined as Entry; (2) products that are exported in period $t-1$ but not exported in period $t$ are defined as Exit; (3) products that are exported in both period $t-1$ and period $t$ are defined as Survival and Deepening.

\subsection{Decomposition Analysis of China's Manufacturing Exports}

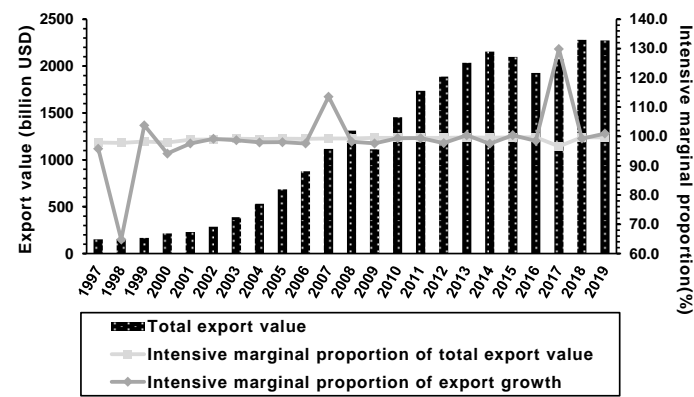

Figure 1 Total value and value growth of China's manufacturing export trade after decomposition from 1997 to 2019

First of all, as shown in Figure 1, except for around 2009 and 2016, the total export value of China's manufacturing trade has always been in a continuous growth trend, but the growth rate has slowed down after 2018. From the perspective of dual margin, we can find that the intensive margin generally accounts for an absolute proportion of total value and growth in China's manufacturing industry. Therefore, it can be considered that under the four-dimensional dynamic decomposition, the intensive margin dominates the export trade and export growth of China's manufacturing industry. On the other hand, whether from the perspective of total export value or export growth, the performance of export data around 2009, 2015, and 2019 can fully reflect that external shocks have a very large impact on China's manufacturing export trade. The external shocks embodied in the former two may be manifested in the impact of the global financial crisis and aftershocks, while the latter may be more reflected in the trade war provoked by Western developed countries represented by the United States against China.

Furthermore, the changes in the number of trade relations in various parts of China's manufacturing exports are shown in Figure 2. It can be found that
Survival and Deepening, which also occupies an absolute proportion in quantity, has always maintained a growth trend over the years. Compared with Survival and Deepening, the magnitude of the changes in the number of Entry and Exit trade relations is not particularly large, so their proportion in the overall trade relations also decreases over time. However, it should be noted that at certain specific points in time, the growth rate of Entry and Exit trade relations fluctuates particularly sharply. For example, around China's accession to the WTO in 2001, the growth rate of Entry dropped suddenly, while the growth rate of Exit changed in the opposite direction. This shows that for Chinese manufacturing companies, although China's WTO accession has created more opportunities to participate in the international market and a better policy environment, it has also made the international competition faced by export companies more intense. Another example is the high Exit growth rate and low Entry growth rate around 2008 and 2015, which once again reflect the huge impact of external shocks on China's manufacturing exports.

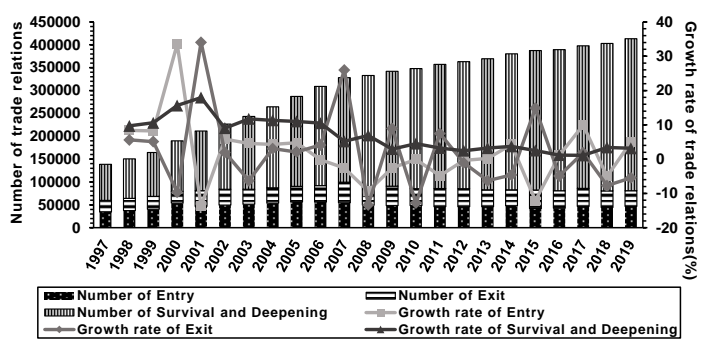

Figure 2 Total number and number growth of China's manufacturing export trade after decomposition from 1997 to 2019

Finally, if we simply focus on the export value of survival and deepening trade relations, the result is shown in Figure 3. The deepening rate here is not the growth rate of the total intensive marginal export value of the current year relative to that of the previous year, but the growth rate based on the export value of total Survival and Deepening products in the current year and the previous year. It can be found that the overall fluctuation of the deepening rate is relatively drastic. The years when the deepening rate was low or negative values were also those years suffering from external shocks such as the financial crisis and trade war. In the years after the shock subsided, the deepening rate tends to first recover to an extremely high point, and then gradually decreases and stabilizes over time. This data performance once again reflects the huge impact of external shocks on China's manufacturing exports, and on the other hand, it may also indicate that Chinese manufacturing export companies may not have an advantage in long-term international competition. 


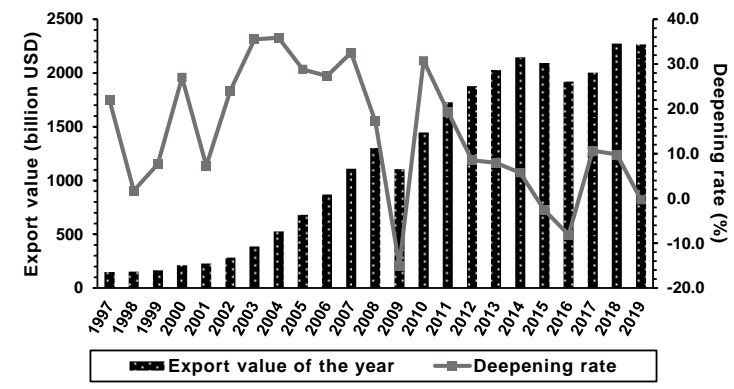

Figure 3 Export value and deepening rate of Survival and Deepening in China's manufacturing export trade from 1997 to 2019

\section{CONCLUSION}

After a four-dimensional dynamic decomposition, whether it is the overall export value or the export growth value, the intensive margin representing Survival and Deepening has an absolute proportion. This shows that under the four-dimensional dynamic decomposition, China's manufacturing export trade and export growth are both dominated by the intensive margin, and the export growth is still mainly dependent on the export of existing products. In addition, the changes in the number of trade relations and the intensification rate indicate that China's manufacturing exports are more affected by external shocks. The rate of deepening also reflects that Chinese manufacturing export companies may not have advantages in long-term international competition.

\section{ACKNOWLEDGMENTS}

First of all, I would like to express my sincere gratitude to my supervisor, Mr. Deng Jing, who has offered me inspiring advice in the academic studies. Without his active encouragement and patient guidance, this thesis could not have been completed so smoothly. I also want to thank my parents for excluding interruptions from other relatives and creating a quiet environment suitable for writing. Finally, I would like to thank my roommates for their company and encouragement in the process of writing my thesis.

\section{REFERENCES}

[1] A. Amurgopacheco, M.D. Piérola, Patterns of export diversification in developing countries : intensive and extensive margins, in: Policy Research Working Paper, World Bank, 2007. DOI: https://doi.org/10.1596/1813-9450-4473

[2] X. Huang, J. Zhou, Geographical Expansion and Product Expansion in China's Export Expansion with Their Structural Optimization. Management World. (10) (2011) 20-31. DOI: https://doi.org/10.19744/j.cnki.111235/f.2011.10.003
[3] D. Hummels, P. J. Klenow, The Variety and Quality of a Nation's Exports. American Economic Review. 95(3) (2005) 704-723. DOI: https://doi.org/10.1257/0002828054201396

[4] B. Shi, The Three Margins of China's Export Growth. China Economic Quarterly. 9(04) (2010) 1311-1330.

DOI: https://doi.org/10.13821/j.cnki.ceq.2010.04.008

[5] M. Amiti, C. Freund, An Anatomy of China's Trade Growth, in: Policy Research Working Paper, World Bank, 2007. DOI: http://dx.doi.org/10.1596/18139450-4628

[6] A. B. Bernard, J. B. Jensen, S. J. Redding, P. K. Schott, The Margins of US Trade. American Economic Review. 99(2) (2009) 487-493. DOI: https://doi.org/10.1055/s-2003-42658

[7] T. Besedes, T. J. Prusa, The Role of Extensive and Intensive Margins and Export Growth. Journal of Development Economics. 96(2) (2011) 371-379. DOI: https://doi.org/10.1016/j.jdeveco.2010.08.013

[8] F. Zhang, D. Feng, D. Liu, Study on the Fourdimensional Dynamic Structure Decomposition of China's Export Growth and Its Influencing Factors. The Journal of Quantitative \& Technical Economics. 36(09) (2019) 61-80. DOI: https://doi.org/10.13653/j.cnki.jqte.20190906.004

[9] A. B. Bernard, J. B. Jensen, Firm Structure, Multinationals, and Manufacturing Plant Deaths. The Review of Economics and Statistics. 89(2) (2007) 193-204. DOI: https://doi.org/10.1162/rest.89.2.193

[10] L. Gao, X. Qu, P. Jia, Do Foreign Firms Have Higher Exit Probability?. The Journal of World Economy. 40(07) (2017) 52-77. DOI: CNKI:SUN:SJJJ.0.2017-07-004 